\title{
Does working alliance have an influence on pain and physical functioning in patients with chronic musculoskeletal pain; a systematic review
}

\author{
Sandra E. Lakke* and Sebastiaan Meerman
}

\begin{abstract}
Background: Working alliance can possibly influence patients' experiences of pain and physical functioning. The aim of this systematic review is to merge evidence from literature regarding the influence of patients' perceived working alliance on pain and physical functioning in patients with chronic musculoskeletal pain.

Methods: A systematic review in which randomized controlled trials and cohort studies were included that assessed the influence of working alliance on either pain or physical functioning in patients with chronic musculoskeletal pain. The methodological quality of the included studies were rated by means of the PEDro score and STROBE statement.

Results: The first step of the search process provided 1469 studies. After screening, five studies were included in this review including one RCT and four cohort studies of patients with chronic musculoskeletal pain. One cohort study was rated as low methodological quality and the other studies as high methodological quality. There was a significant effect of working alliance on the outcome of pain severity, pain interference, and physical functioning in all studies. Physical functioning was measured by means of questionnaires and functional capacity tests. The effect on questionnaires was positive; the effect was conflicting on functional capacity.
\end{abstract}

Conclusion: When influencing pain with treatment, a patient's perceived working alliance during treatment does predict pain reduction and improvement in physical functioning. It is recommended to inquire about a patient's working alliance during treatment in patients with chronic musculoskeletal pain.

Keywords: Working alliance, Musculoskeletal pain, Pain, Review, Functional capacity

\section{Background}

Musculoskeletal pain is the number one causal reason for restricted participation at work which subsequently places a significant financial burden on society $[1,2]$. In regard to physical therapy, there are two possible methods to minimize health care costs: reduce the risk and prognostic factors and offer patients the most effective treatment. When attempting to reach this latter goal, it is important to focus towards improving the effectiveness of treatments. One of the substances of physical

\footnotetext{
* Correspondence: a.e.jorna-lakke@pl.hanze.nl

International Health Care School, Physiotherapy, Hanze University of Applied Sciences, 3109Eyssoniusplein18, Groningen 9701DC, The Netherlands
}

therapy treatment that might influence the effectiveness of conventional physical therapy treatments is the working alliance. A positive working alliance rating between physical therapists and patients is assumed to be associated with improvements of outcomes [3-9].

A general definition of working alliance is: "The patient and the therapist work well together" [6]. Working alliance might also be referred to as 'helping alliance' or 'therapeutic alliance' in other literature [4]. Working Alliance has been described often. S. Freud referred to it in 1912 as "A sense of collaboration, warmth, and support between the client and therapist" [10]. This personal bond between the therapist and patient strengthens a 
patient's participation in therapy and the compliance to therapy, thereby allowing a prediction of increased treatment results $[6,10,11]$. Therapists could enhance the personal bond by exhibiting compassionate health care, which is described as person centred care in which therapists demonstrate characteristics such as empathy, sensitivity, kindness and warmth [12]. The term 'alliance' emerged in 1934 for the first time [13]. Later, in 1979, Bordin described that working alliance comprised three constructs including agreement on goals, collaboration with tasks, and establishment of the bond between patient and therapist [14]. Based on these three constructs, the Work Alliance Inventory (WAI) was created to measure working alliance [15]. The latter three constructs will be used as the definition of working alliance throughout this study.

Governments of several countries all over the world support positive relationships with patients and encourage shared decision making (SDM) although evidence for the association between SDM and the secondary health outcomes of pain, physical functioning, or behavior is lacking [16]. The construct of working alliance resembles a patient's perception of shared decision making (SDM). SDM is defined as an optimal approach to making health care decisions [16-20]. Patients describe the decision-making process as shared when two or more parties mutually agree and make a decision [21]. The perceived agreement in SDM resembles two factors of the working alliance construct, i.e. agreement on goals and tasks, and may lead to adherence and re-enforce patient autonomy [22]. In the medical context, a patient's perceived level of shared decision making improves the primary affective-cognitive outcomes of treatment, e.g., understanding, satisfaction, and trust [16]. Gaining insight into the effects of working alliance on pain and physical functioning may possibly provide substance to the widespread support for SDM [23].

In 2010, a first review was published which indicates a positive correlation between working alliance and several treatment outcomes [4]. In that review, the patient population suffered from a wide variety of health conditions including brain injury, musculoskeletal conditions, cardiac conditions, and other multiple pathologies. A diversity of treatment outcomes have been analyzed such as pain, physical functioning, satisfaction with treatment, depression, and general health status [4]. The previous study did not judge the methodological quality as recommended by the Cochrane collaboration group which may have induced a risk of bias [24]. The search strategy of that review was executed until February 2009. Since that time, other articles have been published, therefore, an updated review is required in order to determine the current level of evidence of working alliance during physical therapy in patients with musculoskeletal pain.
Reduced pain and improved physical functioning are the primary outcome variables in physical therapy. This review, therefore, will focus on the influence of working alliance on either pain or physical functioning in patients with chronic musculoskeletal pain.

\section{Methods}

The literature study and analyses were conducted by the two authors of this study. The study was originally performed by the second author, who was a student writing a Bachelor of Science thesis on physical therapy at the Hanze University. In a second stage, the first author, who has published several systematic reviews in peer reviewed journals, repeated the search and data extraction.

\section{Search strategy}

Articles were searched for in multiple databases: Pubmed, Cinahl, Embase, Ovid, AMED, ProQuest Dissertations \& Theses, and PsychINFO. As an example of search terms the following, among others, have been utilized: Musculoskeletal, physical therapy, musculoskeletal disease $(\mathrm{MeSH})$, working alliance, therapeutic alliance, helping alliance, work alliance index, session rating scale, pain, functioning, physical functioning, pain level, pain experience, treatment outcome, pain $(\mathrm{MeSH})$, musculoskeletal pain $(\mathrm{MeSH})$, and physical fitness $(\mathrm{MeSH})$. For a comprehensive description of the search terms, including search strings, see Additional file 1. The references of systematic reviews that have been published concerning working alliance, but not specifically pain or physical functioning, were examined.

\section{Literature selection}

The search strategy was conducted for articles from 1980 until July 1, 2015. The articles were screened on the basis on their title or abstract. The full text was monitored in a second screening for the articles that remained valid following the first screening. The inclusion criteria were:

- The studies were required to be written in either English or Dutch.

- The patient category that was employed in a study had to match the description of chronic musculoskeletal pain, i.e., pain of the upper and lower limbs, neck, and lower back with a duration of more than three months.

- Studies were included that, first, measured working alliance as an active ingredient of the intervention that was consciously applied during therapy and, secondly, measure working alliance as an unconsciously delivered element of the intervention that was measured in patients and analyzed as a 
prognostic factor on the outcome variables of pain or physical functioning. Studies were included if the intervention itself was a customary physical therapy related treatment. The definition of working alliance comprised one or all of the three constructs of working alliance mentioned in the introduction section: agreement on goals, collaboration on tasks, and establishment of the bond between patient and therapist. [14]

- The following study designs were included: RCT, CCT, and cohort studies. Studies with a qualitative study design were excluded.

- The studies must have had either pain or physical functioning as an outcome measurement.

- The included studies had to reach a certain degree of quality to be able to make recommendations. Therefore, items three and four of the PEDro score were positively scored because of the importance of subject blinding and having similar groups at baseline within an RCT and CCT design.

\section{Methodological quality assessment}

The quality assessment tool depends on the study design:

For an RCT/CCT design: When measuring the quality of an RCT, the PEDro score is a reliable measurement tool [25]. The PEDro scale appears to have sufficient reliability for use in systematic reviews of physical therapy RCTs and provides a solid basis for research [25]. To be considered as having high methodological quality, the total score must be between six and eight out of ten [26]. A score of nine or ten is considered as very high methodological quality [26]. A score of four or five can be considered as fair quality. If the article scores lower than four points, the methodological quality can be considered as poor [26].

For a Cohort design: The methodological quality of a longitudinal cohort study were assessed by utilizing the STROBE (Strengthening the Reporting of Observational Studies in Epidemiology) Statement 2007 [27]. The STROBE Statement is widely accepted as a valuable tool to assess the methodological quality in studies with longitudinal study design [27]. A score higher than 17 out of 22 points were considered as high quality. A score lower than or equal to 17 were considered as low quality. Note that this score was not based on literature as there is no literature describing what should be considered a high or low methodological quality score.

\section{Data extraction}

Both authors extracted the data from the studies that were included. The articles have been thoroughly analyzed, and the following quantitative data have been extracted: the author and year of publication; the study type; the number of patients that participated in the research; baseline pain and function measurement; the intervention that the participants received; the alliance measurement that was used; the measurement tool of the outcome; a description of the outcome measurement; the outcomes of the intervention; and the significant results of the statistical analyses. For the RCT's, the between group analyses were extracted from the study. From the longitudinal cohort studies, the statistical within group analyses between start and end measurements were extracted. Additionally, for the cohort studies, the correlation coefficient and regression coefficients of working alliance on the outcome of treatment will be extracted from the included studies.

\section{Data analysis}

The results of the methodological quality scores and the positive, negative, or no results of the included studies were shown in a table. RCTs and cohort studies were shown separately.

Note that the methodological quality of the RCT was assessed by employing the PEDro score, and the STROBE Statement was used for the cohort studies.

\section{Results \\ Included studies}

During the course of the search process, 1469 articles were selected as eligible. Subsequently, these articles were analyzed again based on their abstract, duplicates, and/or title. A total of 16 articles remained. After applying the inclusion and exclusion criteria, five final articles were selected $[5,28-31]$. Visualization of the selection of articles is indicated in Figure 1. The included studies were written between 1997 and 2014. Only one of the studies was an RCT [31]. From the five included studies, two were unpublished dissertations with a longitudinal design $[28,29]$.

\section{Methodological quality}

The RCT had a very high methodological quality. It was not possible to blind the therapist. [31] From the four included cohort studies, three were of methodological high quality $[5,29,30]$. The methodological quality of the selected articles can be reviewed in Table 1 . In Additional file 2, a comprehensive overview of the scoring of the methodological quality is depicted.

\section{Participants}

Combining all of the articles, 1041 patients were included in this review from the USA, Germany, Australia, and Canada. In four studies, the patient population consisted of chronic low back pain patients (CLBP) that had been experiencing pain for more than three months and, in the study of Farin, the inclusion criterion was having 


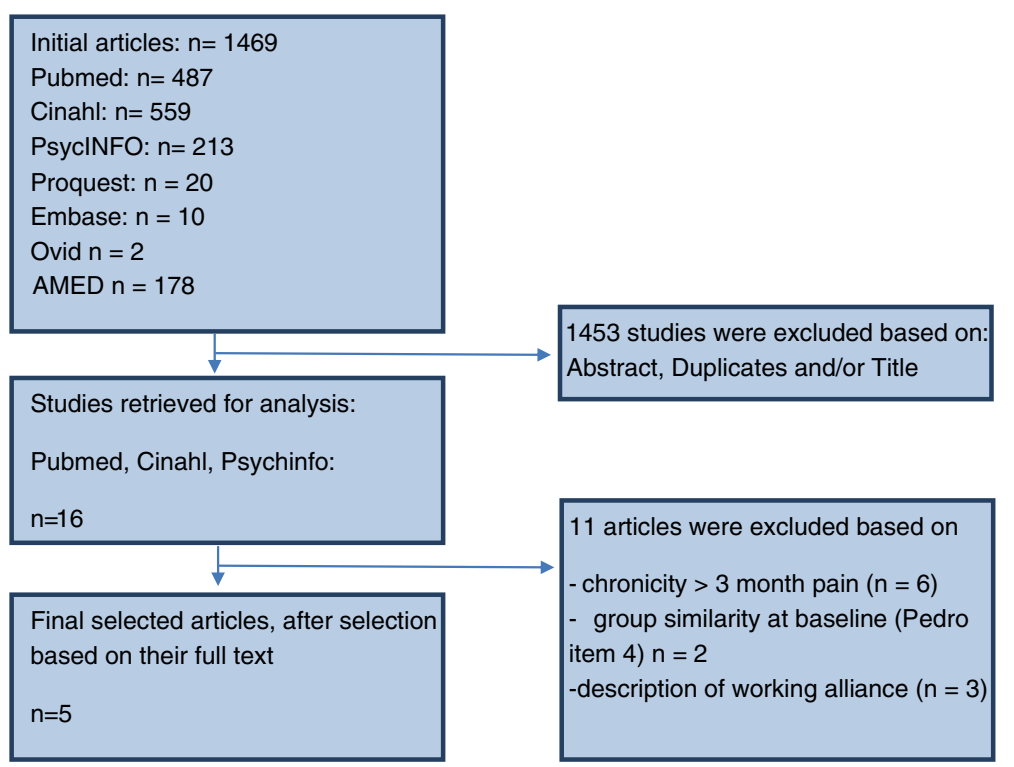

Fig. 1 Literature selection process

pain for more than six months (Table 2). In three studies, patients with specific musculoskeletal pain were excluded, i.e., pain of the upper and lower limbs, neck, and lower back that is not attributed to a recognizable specific pathology such as infection, tumor, osteoporosis, ankylosing spondylitis, fracture, inflammatory process, radicular syndrome, or cauda equina syndrome [5, 30-32]. The mean age of all included patient populations varied between 29.7 and 54.2 years old.

\section{Intervention}

In Table 2 the time span of the intervention is described (Table 2). It ranges from a single session to an eight week program. In the studies, the intervention consisted of treatment options regularly used by physical therapists, particularly, non-specified physical therapy, general exercise, motor control exercise, spinal manipulative therapy, and interferential current therapy (IFC). Interferential current therapy is an electrotherapy for pain sedation at a comfortable sensory level that produces a 'pins-and-needles-like sensation' without stimulating visible muscle twitches. An overview of the interventions can be found in Table 2 .

Table 1 Methodological quality rating

\begin{tabular}{lll}
\hline Author \& year & Methodological score & Quality rating \\
\hline Cohort studies & & \\
Higdon 1997 [28] & $14 / 22$ & Low \\
Bliss 2009 [29] & $18 / 22$ & High \\
Farin et al. 2012 [30] & $20 / 22$ & High \\
Ferreira et al. 2013 [5] & $20 / 22$ & High \\
Randomized controlled trial & & \\
Fuentes et al. 2014 [31] & $9 / 10$ & High \\
\hline
\end{tabular}

\section{Working alliance measurement}

Between the articles, four different measurement tools were utilized to measure the alliance between patient and therapist. The most commonly used was the WAI, which was employed in three out of five studies [5, 28, 29]. It is important to realize that the moments of measurement differed and ranged from a measurement after the first treatment and a measurement after the complete rehabilitation program. In the cohort studies, the working alliance has been used as a process factor which is predictive of the treatment result. The one RCT used the working alliance as an active intervention additional to the treatment of interferential therapy. In that RCT, interferential therapy was applied in both study groups. In one group, the working alliance was enhanced by additionally applying $10 \mathrm{~min}$ of patient-centered communication. In the group that solely received interferential therapy, the therapists had been instructed to avoid conversation during the treatment. In the group that received the additional patient-centred communication, the enhanced working alliance was created by enhancing verbal behavior including active listening, changing the tone of voice, implementing nonverbal behavior, and demonstrating empathy.

\section{Data extraction}

Different statistical analyses have been used among the articles. In the RCT, an in-between group analysis was utilized meaning that the effect of the treatment between the two groups was calculated after treatment. The cohort studies used regression analyses to provide a statistical value which indicates that an estimation of the relationships between several treatment variables was provided. A 
Table 2 Description of included cohort studies and one Randomized controlled study

\begin{tabular}{|c|c|c|c|c|c|c|c|c|c|}
\hline \multirow[t]{2}{*}{ Author } & \multirow{2}{*}{$\begin{array}{l}\text {-Country, Number of patients (\% female), } \\
\text { Inclusion criteria, Age (y) Mean(SD), } \\
\text { Duration of pain (mnth), Mean(SD), } \\
\text { Intervention, therapists }\end{array}$} & \multirow[t]{2}{*}{ Working alliance } & \multicolumn{3}{|c|}{ Dependent variable measurement } & \multicolumn{3}{|c|}{$\begin{array}{l}\text { Influence of Working } \\
\text { alliance }\end{array}$} & \multirow[b]{2}{*}{ Qality } \\
\hline & & & & Pre & Post & $r$ & $B$-value & $R^{2}$ & \\
\hline \multicolumn{10}{|l|}{ Cohort studies } \\
\hline \multirow[t]{8}{*}{$\begin{array}{l}\text { Higdon [28] } 1997 \\
\text { Cohort }\end{array}$} & & & Pain & & $\begin{array}{l}3 \text { months after } \\
\text { therapy end }\end{array}$ & & & & $14 / 22$ \\
\hline & \multirow{7}{*}{ 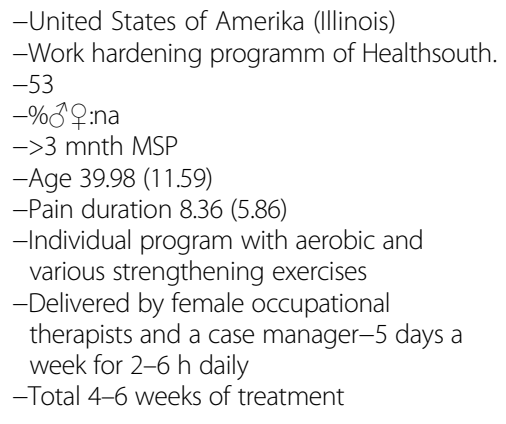 } & \multirow{7}{*}{$\begin{array}{l}\text { WAI 12-item (12-60) } 8 \\
\text { days after start of treatment }\end{array}$} & Pain Severity (MPI) (0-7) & $3.19(1.11)$ & $2.92(1.22)$ & & na & na & \\
\hline & & & Pain Interference (MPI) (0-7) & $3.70(1.16)$ & $3.23(1.32)^{*}$ & & na & na & \\
\hline & & & Activity & & Therapy end & & & & \\
\hline & & & Floor/Bench & $44.58(22.50)$ & $54.97(21.59)^{*}$ & $.27^{*}$ & .26 & $.07^{*}$ & \\
\hline & & & Overhead lift & $31.33(12.85)$ & $40.83(13.56)^{*}$ & ns & $\mathrm{np}$ & $\mathrm{np}$ & \\
\hline & & & Push/Pull & $66.81(15.40)$ & $74.42(22.67)^{*}$ & ns & $\mathrm{np}$ & $\mathrm{np}$ & \\
\hline & & & Carrying & $43.57(21.72)$ & $55.39(23.42)^{*}$ & ns & $\mathrm{np}$ & $\mathrm{np}$ & \\
\hline \multirow{3}{*}{$\begin{array}{l}\text { Bliss [29] } 2009 \\
\text { Cohort }\end{array}$} & & & Pain & & Therapy end & & & & $17 / 22$ \\
\hline & \multirow{2}{*}{$\begin{array}{l}\text {-United States of Amerika (Indiana) } \\
\text {-Outpatient rehabilitation clinics and } \\
\text { multidisciplinary pain clinics } \\
\text { - } 59 \\
-67 \% \text { \% }->3 \text { mnth CLBP } \\
\text {-Age } 47.47 \text { (14.14) } \\
\text {-Pain duration } 74.36 \text { ( } 83.76 \text { ) } \\
\text {-Exercises, not specifically mentioned } \\
\text {-Delivered by Physical Therapists } \\
\text {-Total } 5 \text { weeks }\end{array}$} & \multirow[t]{2}{*}{$\begin{array}{l}\text { WAI 12-item (12-60) } 5 \text { weeks } \\
\text { after start of treatment }\end{array}$} & Pain severity $(\mathrm{BPI})(0-40)$ & & $\begin{array}{l}\text { Change } 4.21 \\
(9.3)^{*}\end{array}$ & $.29^{*}$ & .29 & $.08^{*}$ & \\
\hline & & & Pain Interference (BPI)(0-70) & & $\begin{array}{l}\text { Change } 4.95 \\
(13.8) \text { (ns) }\end{array}$ & $.29^{*}$ & .30 & $.08^{*}$ & \\
\hline \multirow{8}{*}{$\begin{array}{l}\text { Farin [30] } 2012 \\
\text { Cohort }\end{array}$} & & & Pain & & Therapy end & & Risk factor & & $20 / 22$ \\
\hline & \multirow{7}{*}{$\begin{array}{l}\text {-Germany (several regions) } \\
\text { - Inpatient and outpatients } \\
\text { orthopedic rehabilitation centers } \\
\text { - } 688 \\
-57.2 \% \text { \% } \\
\text { - } 497 \text { employed } \\
\text { - } 6 \text { mnth CLBP } \\
\text { - Age } 51.0(11.2) \\
\text {-Pain duration } 13.0 \% \text { (<12 mnth), } \\
29.7 \text { ( } 12-60 \text { mnth), } 56.5 \% \text { (>72 mnth), } \\
0.8 \% \text { unknown } \\
\text { - Various interventions. Aerobic, } \\
\text { strengthening }\end{array}$} & \multirow{7}{*}{$\begin{array}{l}\text { PHYSAT (0-10) At the } \\
\text { end of therapy }\end{array}$} & Pain severity (VAS (0-100) & $52.9(22.7)$ & $41.35(22.77)$ & na & $1.44^{* a}$ & & \\
\hline & & & & & 6 months after & & $\begin{array}{l}6 \text { months } \\
\text { after }\end{array}$ & & \\
\hline & & & & & $40.22(36.04)$ & & $1.15^{* a}$ & & \\
\hline & & & Activity & & Therapy end & & & & \\
\hline & & & ODI (0-100) & $31.11(15.87)$ & 26.15 (15.96) & na & $1.23^{*}$ & & \\
\hline & & & & & 6 months after & & $\begin{array}{l}6 \text { months } \\
\text { after }\end{array}$ & & \\
\hline & & & & & $23.9(17.14)$ & & $.75^{*}$ & & \\
\hline
\end{tabular}


Table 2 Description of included cohort studies and one Randomized controlled study (Continued)

-Delivered by various professional groups

(physicians, physical-, occupational-, and

sport therapists, psychologists)

-3 weeks, $4-5$ therapy sessions a

day on workdays

Ferreira [5] 2013

Cohort

$$
\begin{aligned}
& \text {-Australia (Sydney) } \\
& \text {-Outpatient hospital physical therapy } \\
& \text { departments } \\
& \text { - } 182 \\
& \text { - } 9(70.0 \% \text { GE, } 66.3 \% \text { MCE, } 70.0 \% \text { SMT) } \\
& \text {->3mth CLBP } \\
& \text {-Age } 54.2(15.4) \\
& \text {-Pain duration median } 60 \text { (GE), } \\
& 36 \text { (MCE), } 84 \text { (SMT) } \\
& \text {-General exercise (GE), or Motor } \\
& \text { control exercise (MCE), or spinal } \\
& \text { manipulation (SMT) } \\
& \text {-Delivered by } 7 \text { experienced } \\
& \text { physical therapists } \\
& \text {-8 weeks } 12 \text { sessions of treatment }
\end{aligned}
$$

Randomized Controlled Trial

Fuentes [31] 2014

$\mathrm{RCT}$

$$
\begin{aligned}
& \text {-Canada (Edmonton) } \\
& \text {-Sport physical therapy laboratory } \\
& -59 \\
& -I(n=29) 65.5 \% \text { q } \\
& -C(n=30) 60.0 \%+ \\
& ->3 \text { Mo CLBP } \\
& \text {-Age, I 29.7(11.33); C 30.5(10.26) } \\
& \text {-Pain duration, I 51.21(38.30); C } 45.3 \text { (56.76) } \\
& \text { - Ine interferential therapy during } 30 \text { min. } \\
& \text { at comfortable sensory level } \\
& \text {-C One interferential therapy and a } \\
& 10 \text { min. working alliance intervention } \\
& \text {-Delivered by } 3 \text { experienced female } \\
& \text { physical therapists that were trained } \\
& \text { in patient-therapeutic interactions by } \\
& \text { a clinical psychologist }
\end{aligned}
$$

Pain

$$
\begin{array}{lll}
\begin{array}{l}
\text { WATOCI (16-112) 2nd } \\
\text { treatment }
\end{array} & \text { Pain severity VAS (0-10) } & \text { GE 6.5 (2.1)MCE } \\
& & 6.3(2.0) \text { SMT } 6.2
\end{array}
$$

Therapy end

Activity

RMDQ (0-24)

GE 13.9 (5.4) MCE

14.0 (5.3) SMT $12.4(5.8)$ na na $\quad-.0495 \%$

to -.017$)^{*}$

$-1195 \%$

$-.060)$
Pain

Pain severity NRS (0-10)

Muscle pain sensitivity PPT 1st treatment session

I: 0.89 (0.98)

C: 2.18 (1.17)

MD: $-12.949,95 \%$

Cl $(-18.766 \text { to }-7.132)^{*}$

$4.11(1.8) \quad$ I: $6.21(2.6)$

$\begin{array}{ll}\text { C: } 3.89(1.8) & \text { C: } 5.15(2.6)\end{array}$

MD: $-0.856,95 \%$

$\mathrm{Cl}(-1.682$ to -0.030$)$ after

Bonferroni correction ns

$N$ number of participants, ${ }^{*}$ sign difference $(p<0.05)$, ns not significant; na, not applicable ( not mentioned or analyses is not performed), BPI, Brief Pain Inventory pain severity scale and pain interference scale on functioning. (rate the level of interference that pain has caused in the last $24 \mathrm{~h}$ on specific domains of functioning like general activity, work etc.), PHYSAT consisting of 3 items (the physician showed empathy and understanding; the physician explained my symptoms in a way I understood; the physician arranged the proper therapy for me. PPT ( $\left.\mathrm{kg} / \mathrm{cm}^{3} / \mathrm{s}\right)$, pressure pain threshold, Cl confidence interval, WATOCI Working alliance Theory of Change Inventory, RMDQ Roland-Morris Disability Questionnaire (0-24), ODI Oswestry Disability Index; ccohort study; RCT Randomized controlled trail, MSP musculoskeletal pain, Mnth months, y, years, $r$, correlation, $R^{2}$ regression coefficient; ${ }^{a}$, predictor's regression coefficient (Risk factor); ${ }^{b}, 10$ min questioned and therapeutic interaction was enhanced through verbal behaviours including active listening, tone of voice, nonverbal behaviors and empathy, to create an optimal clinician patient relationship; PT physical therapist; MD mean difference; I intervention group IFT with working alliance, CControl group IFT without working alliance; $n p$ not performed, for those variable demonstrating no significant relationships no regression analysis was performed 
regression analysis provides a $B$-value [33]. In a case where pain is the dependent value, a change of one point on the working alliance scale will increase or decrease the painvalue on the used measurement tool as much as the $B$ value indicates. The $B$-value can be interpreted the same way for the outcomes of physical functioning. Additionally, in a regression analysis, an $\mathrm{R}$ [2] value is provided as a percentage which indicates the effect of the independent variable on the dependent variable [33]. In the first article in Table 2, an $\mathrm{R}$ [2] value of 0.07 can be seen as that working alliance predict $7 \%$ of the change in patient's pain rating between the start en end of therapy.

\section{Measurements}

All of the included studies have an outcome measurement of either pain or physical functioning. For the outcome pain, all studies used pain severity as the outcome measure, and two articles added pain interference. Pain interference assessed the degree to which pain is impacting the subject's life. For the outcome physical activity, three articles used physical activity as the outcome measure whereby one article of the three used functional capacity evaluation that resembles the maximal level of work activities. The regression analysis of the floor/bench test are described in the study, however, the other three functional capacity tests are not described [28]. Several articles have additional outcome measures such as global perceived effect, quality of life, lifting capacity, walking endurance, depression, hostility, anger, and pressure pain sensitivity. Though these additional outcome measures will be disregarded in the result section, it is still important to take note of these possible confounders. For a full description and overview of the used outcome measures, including the measurement tools, see Table 2.

\section{Results of the studies}

There was an effect of working alliance on the outcome of pain reduction, pain interference, and physical functioning (activity) directly after treatment, at the end of therapy, three months after therapy ended, and six months after therapy ended (Table 2). There was an effect of working alliance on the outcome physical functioning measured by the two questionnaires Oswestry Disability Index (ODI) and Roland-Morris Disability Questionnaire (RMDQ), and the functional capacity measurement Floor/Bench test. The relation of working alliance on overhead lifting, push pull, and carrying were not significant and were therefore excluded from the regression analysis [28].

\section{Data analysis}

RCT: The results from one RCT revealed that a patientcentred intervention to consciously enhance working alliance contributed to a reduction in pain severity (Table 3) [31]. Additionally, there is evidence from one RCT that working alliance does not contribute to muscle pain sensitivity (Table 3) [31]. RCT: Physical functioning: The included RCT does not provide results regarding physical functioning [31].

Cohort: Pain: The results of the cohort studies regarding pain severity show strong evidence that working alliance contributed to a reduction of pain. There were a total of three high quality studies that indicated positive results of reduced pain severity [5, 29, 30]. From one high quality and one low quality cohort study, there is evidence that working alliance contributed to pain interference of patients with chronic low back pain.

Cohort: Physical functioning. There are three cohort studies, two of high quality and one of low quality, in which working alliance contributed to improved physical functioning $[5,28,30]$.. Two studies also showed high methodological quality $[5,30]$. Working alliance contributed positively to the ODI, RMDQ, and the Floor/Bench lifting test. The other functional capacity tests, overhead lift, push/pull and carrying, were not correlated to working alliance (Table 2).

\section{Discussion}

The goal of this systematic review is to merge evidence from literature regarding the influence of patients' perceived working alliance on pain and physical functioning in patients with chronic musculoskeletal pain. The

Table 3 Overview of the contribution of working alliance on pain and physical functioning

\begin{tabular}{|c|c|c|}
\hline & RCT & Cohort \\
\hline Pain Severity & 1 high & 3 high \\
\hline Muscle pain sensitivity & 1 high & -- \\
\hline Pain Interference & -- & 1 high, 1 low \\
\hline Physical Functioning & -- & 2 high, 1 low \\
\hline
\end{tabular}

Green, positive contribution of working alliance; Red, no contribution to working alliance;; --, no evidence found in literature.

Number of studies with methodological quality (high or low) 
intention was to conduct another review when new articles had been published. Based on the cohort studies that have been included in the research, it appears that there is evidence that working alliance contributes to pain reduction and evidence that working alliance contributes to physical functioning measured by means of questionnaires in patients with chronic musculoskeletal pain (Table 3). Additionally, there is evidence of the influence on pain interference. The influence of working alliance on treatment results is small but significant.

The results of this review underpin the results found in the previous review of Hall that working alliance had an influence on pain [4], even though the current review included an additional three studies $[5,30,31]$ and did not include the results of one dissertation that was beyond the strict inclusion criteria of this review [34]. Moreover, the results resemble those in a review of the influence of working alliance in psychotherapy [3]. Taking into account the latter results, it could be concluded that there is strong evidence that a patient's perception of working alliance has an influence on the results of therapy as evidenced by pain and physical functioning.

Patient-centred communication is related to a patient's perceived positive working alliance [35]. Working alliance was measured in most of the included studies with the WAI that comprised agreement on goals, collaboration with tasks, and establishment of the patienttherapeutic bond $[14,15]$. Constructs that are related to a sense of positive working alliance are, first, allowing patient involvement in the consultation process that may influence the WAI construct agreement on goals, second, the trust that could influence the WAI construct collaboration with tasks; and, third, emotional support that can influence the establishment of the patienttherapeutic bond [35]. It is recommended to study the relation between the latter causative factors for a positive perception of working alliance.

As in all reviews, this review could have been biased based on the included studies and the method used for this review. There could possibly have been a language bias based upon the fact that only English and Dutch studies are included. During our intensive search, there were no other studies that we could not include based on the language. The studies that were included were performed in the USA, Germany, Australia and Canada. We may have missed studies that were performed in other countries. Additionally, there was heterogeneity between the number and age of patients, the measurement instruments, the time of treatment session for gathering the information of working alliance, and the outcome measurements of especially physical activity. The number of patients differed from 53 to 688 patients and were not taken into account during analyses. Studies were not excluded based on the age of patients because there is a limited availability of studies. However, in future research concerning working alliance, it would be interesting to take the age of the patient population into consideration because the effect of age on pain sensitivity and pain perception is evident [36, 37]. Another confounding variable may possibly have been the duration of pain and pain severity at baseline. Yet the results of one study that included patients that had suffered pain for more than six months resembled the results of the other included studies [29] and there were no pregnant differences of pain severity at baseline between included studies (Table 2). It is unknown what effect the diversity of interventions and the amount and quality of communication during intervention had on the results of a patient's perception of working alliance and therewith the results of this study. Only one study video recorded the therapist's communication during intervention [31]. It is recommended to observe and describe the communication during intervention in future studies on working alliance. The validity and reliability of the measurement instrument of working alliance were good in four of the five studies [5, 28, 29, 31]. In one study, the PHYSAT was used that was not validated [30]. However, if the results of that study were excluded from the best evidence synthesis, it would not affect the results of the best evidence syntheses. The treatment session at which the working alliance was measured differed considerably. The point of measurement of working alliance varied from directly after the first treatment until after the therapeutic program ended. Although the measurement points differ, the influence of working alliance that was measured at the end of all of the treatment sessions was not greater than the effect of working alliance in a study that measured directly after the first session (Table 2). It would be interesting to conduct research where the moment of the application of the working alliance is the primary factor of influence. Finally, the physical activity measurements to measure treatment results of the included studies differed from questionnaires (ODI and RMDQ) to functional capacity tests. Previous studies indicated that psychosocial variables, such as working alliance, are both related to functional capacity and to pain $[38,39]$. Still, this diversity of outcome measurements used in the included studies might have caused a bias on the results of this review. Another bias might have occurred while performing the method of this review. This study was originally performed by the second author who was writing a Bachelor of Science thesis of physical therapy. In a second stage, the first author repeated the search and data extraction. This process could have caused a bias although both authors are very thorough, and the first author has published several systematic reviews in peer reviewed journals. Besides the limitations, there are also strengths in this research. The research 
process has been performed thoroughly following certain criteria beginning with a systematic search for articles, followed by a grading of the methodological quality, and the application of best-evidence syntheses. Thus, a solid systematic review has been compiled.

A recommendation for further research is to perform additional RCT's in which specific aspects of working alliance (agreement on goals, tasks and relation) resulting in additional information about the most active ingredient of working alliance in conjunction with specific subgroups of patients with diverse health conditions, age, specific physical therapy modalities, specific communication styles that can be recorded, and specific outcome measures such as the ODI, RMDQ or functional capacity tests.

The moment of measuring working alliance varied between being studies from directly after the first intervention until after the entire treatment period. Measuring patient's perceptions of working alliance at these diverse points during treatment are predictive for an improved treatment outcome. Therefore, a recommendation to practice is to be sensitive to and measure a patient's perceived working alliance during therapy in order to detect this predictive factor on therapy results. In psychotherapie, the therapist's feedback on a patient's perceived working alliance seems to predict improved psychological functioning [40-42]. Further study is needed on the effect of feedback on pain and physical functioning. Communication skill training might be taken into consideration since it is effective for physical therapists [43].

\section{Conclusion}

When influencing pain during treatment, the working alliance does predict pain reduction and improvement in physical functioning. It is recommended to ask about a patient's perceived working alliance during treatment in patients with chronic musculoskeletal pain, especially when the aim of treatment is pain reduction.

\section{Additional files}

Additional file 1: Search tree. (DOCX $17 \mathrm{~kb}$ )

Additional file 2: Methodological quality studies. (DOCX $14 \mathrm{~kb}$ )

\section{Abbreviations}

WAI: Working alliance inventory; RCT: Randomized controlled trial; CCT: Controlled clinical trial; RMDQ: Roland-Morris disability questionnaire; ODI: Oswestry disability index; PT: Physical therapist.

\section{Competing interests}

No commercial party having a direct financial interest in the results of the research supporting this article has or will confer a benefit on the authors or on any organization with which the authors are associated.

\section{Authors' contribution}

SEL took the initiative about the design of the study, carried out the search string, performed the data extraction and data-analyzes, rewrote and drafted the manuscript. SM carried out the search string, performed the data extraction and data- analyzes, wrote initially and drafted the manuscript. Both authors read and approved the final manuscript.

\section{Acknowledgements \\ This study was funded by the Hanze University, University of Applied Sciences, Physiotherapy, Groningen, Netherlands.}

Received: 9 September 2015 Accepted: 4 January 2016

Published online: 15 January 2016

\section{References}

1. Lambeek LC, van Tulder MW, Swinkels IC, Koppes LL, Anema JR, van Mechelen $\mathrm{W}$. The trend in total cost of back pain in the netherlands in the period 2002 to 2007. Spine (Phila Pa 1976). 2011;36(13):1050-8.

2. Picavet HS, Schouten JS. Musculoskeletal pain in the Netherlands: Prevalences, consequences and risk groups, the DMC(3)-study. Pain. 2003;102(1-2):167-78.

3. Martin DJ, Garske JP, Davis MK. Relation of the therapeutic alliance with outcome and other variables: A meta-analytic review. J Consult Clin Psychol. 2000;68(3):438-50

4. Hall AM, Ferreira PH, Maher CG, Latimer J, Ferreira ML. The influence of the therapist-patient relationship on treatment outcome in physical rehabilitation: A systematic review. Phys Ther. 2010;90(8):1099-110.

5. Ferreira PH, Ferreira ML, Maher CG, Refshauge KM, Latimer J, Adams RD. The therapeutic alliance between clinicians and patients predicts outcome in chronic low back pain. Phys Ther. 2013;93:470-8.

6. Muran JC, Barber JP. The Therapeutic Alliance: An Evidence-Based Guide to Practice. New York: Guilford Press; 2010.

7. Elvins R, Green J. The conceptualization and measurement of therapeutic alliance: An empirical review. Clin Psychol Rev. 2008;28(7):1167-87.

8. Mead N, Bower P. Patient-centredness: A conceptual framework and review of the empirical literature. Soc Sci Med. 2000;51(7):1087-110.

9. Safran JD. The Therapeutic Alliance. Vol ol. 56 (2000) no. 2 (Feb.). New York, NY: Wiley; 2000

10. Freud S, Strachey A, Freud A, Tyson A. The Standard Edition of the Complete Psychological Works of Sigmund Freud. Reprth ed. London: The Hogarth Press and The Institute of Psycho-analysis; 1981. p. 430.

11. Horvath $A O$, Del Re AC, Flückiger C, Symonds D. Alliance in individual psychotherapy. Psychotherapy. 2011;48(1):9-16.

12. Haslam D. More than kindness. J Compliance Health Care. 2015;2(1):1-3.

13. Sterba RF. The fate of the ego in analytic therapy. International journal of psychoanalysis. 1934:117-126

14. Bordin ES. The generalizability of the psychoanalytic concept of the working alliance. Psychother Theory Res Pract. 1979;16(3):252-60.

15. Horvath AO, Greenberg LS. Development and validation of the working alliance inventory. J Couns Psychol. 1989;36(2):223-33.

16. Shay LA, Lafata JE. Where is the evidence? A systematic review of shared decision making and patient outcomes. Med Decis Making. 2015;35(1):114-31.

17. Elwyn G, Tsulukidze M, Edwards A, Legare F, Newcombe R. Using a 'talk' model of shared decision making to propose an observation-based measure: Observer OPTION 5 item. Patient Educ Couns. 2013;93(2):265-71.

18. Elwyn G, Frosch D, Volandes AE, Edwards A, Montori VM. Investing in deliberation: A definition and classification of decision support interventions for people facing difficult health decisions. Med Decis Making. 2010;30(6):701-11

19. Coutu M, Légaré F, Stacey D, et al. Occupational therapists' shared decision-making behaviors with patients having persistent pain in a work rehabilitation context: A cross-sectional study. Patient Educ Couns. 2015;98(7):864-70.

20. Joosten EAG, DeFuentes-Merillas L, De Weert GH, Sensky T, Van Der Staak CPF, De Jong CAJ. Systematic review of the effects of shared decisionmaking on patient satisfaction, treatment adherence and health status. Psychother Psychosom. 2008;77(4):219-26.

21. Shay LA, Lafata JE. Understanding patient perceptions of shared decision making. Patient Educ Couns. 2014;96(3):295-301. 
22. Sandman L, Granger BB, Ekman I, Munthe C. Adherence, shared decisionmaking and patient autonomy. Med Health Care Philos. 2012;15(2):115-27.

23. Hoffmann TC, Montori VM, Del Mar C. The connection between evidencebased medicine and shared decision making. JAMA. 2014;312(13):1295-6.

24. Furlan AD, Pennick V, Bombardier C, Van Tulder M. 2009 updated method guidelines for systematic reviews in the Cochrane back review group. Spine. 2009;34(18):1929-41.

25. Maher CG, Sherrington C, Herbert RD, Moseley AM, Elkins M. Reliability of the PEDro scale for rating quality of randomized controlled trials. Phys Ther. 2003;83(8):713-21.

26. Teasell RW, Foley NC, Bhogal SK, Speechley MR. An evidence-based review of stroke rehabilitation. Top Stroke Rehabil. 2003;10(1):29-58.

27. Van den Broucke JP, von Elm E, Altman DG, et al. Strengthening the reporting of observational studies in epidemiology (STROBE): Explanation and elaboration. Int J Surg. 2014:12(12):1500-24.

28. Higdon L. Patient hostility, the working alliance, and treatment outcome in a work hardening center. Chicago: The Herman M. Finch University of health sciences, the Chicago medical school; 1197. p. 120

29. Bliss EL. The roles of Attachment, Depression, and the Working Alliance in Predicting Treatment Outcomes in Chronic Pain Patients Seeking Physical Therapy Services. University of Miami. 2009: 102

30. Farin E, Gramm L, Schmidt E. The patient-physician relationship in patients with chronic low back pain as a predictor of outcomes after rehabilitation. J Behav Med. 2013;36(3):246-58.

31. Fuentes J, Armijo-Olivo S, Funabashi M, et al. Enhanced therapeutic alliance modulates pain intensity and muscle pain sensitivity in patients with chronic low back pain: An experimental controlled study. Phys Ther. 2014;94(4):477-89.

32. Burton AK, Balague F, Cardon G, Eriksen HR, Henrotin Y, Lahad A, et al. Chapter 2. european guidelines for prevention in low back pain : November 2004. Eur Spine J. 2006;15 Suppl 2:S136-68.

33. Field AP. Discovering Statistics using SPSS : (and Sex, Drugs and Rock ' $n$ ' Roll). 2nd ed. London: Sage Publications; 2005. p. 779.

34. Mirsky J. Anger expression, working alliance, and treatment outcome following multidisciplinary chronic pain treatment. in : Illinois institute of technology. Chicago: Illinois institute of technology;2002:118.

35. Pinto RZ, Ferreira ML, Oliveira VC, et al. Patient-centred communication is associated with positive therapeutic alliance: A systematic review. J Physiother. 2012;58(2):77-87.

36. Wandner LD, Scipio CD, Hirsh AT, Torres CA, Robinson ME. The perception of pain in others: How gender, race, and age influence pain expectations. J Pain. 2012;13(3):220-7.

37. Yezierski RP. The effects of age on pain sensitivity: Preclinical studies. Pain Med (USA). 2012;13 Suppl 2:S27-36.

38. Lakke SE, Soer R, Takken T, Reneman MF. Risk and prognostic factors for non-specific musculoskeletal pain: A synthesis of evidence from systematic reviews classified into ICF dimensions. Pain. 2009;147(1-3):153-64.

39. van Abbema R, Lakke SE, Reneman MF, et al. Factors associated with functional capacity test results in patients with non-specific chronic low back pain: A systematic review. J Occup Rehabil. 2011;21(4):455-73.

40. Duncan BL, Miller SD, Wampold BE, Hubble MA, American Psychological Association. The Heart \& Soul of Change: Delivering what Works in Therapy. Secoth ed. Washington, DC: American Psychological Association; 2010.

41. Lambert MJ, Whipple JL, Smart DW, Vermeersch DA, Nielsen SL, Hawkins EJ. The effects of providing therapists with feedback on patient progress during psychotherapy: Are outcomes enhanced? Psychother Res. 2001;11(1):49-68.

42. Hafkenscheid A. The impact of psychotherapy sessions: Internal structure of the dutch session evaluation questionnaire (SEQ). Psychol Psychother. 2009;82(Pt 1):99-111.

43. Murray A, Hall AM, Williams GC, et al. Effect of a self-determination theory - based communication skills training program on physiotherapists psychological support for their patients with chronic low back pain: A randomized controlled trial. Arch Phys Med Rehabil. 2015;96(5):809-16.

\section{Submit your next manuscript to BioMed Central and we will help you at every step:}

- We accept pre-submission inquiries

- Our selector tool helps you to find the most relevant journal

- We provide round the clock customer support

- Convenient online submission

- Thorough peer review

- Inclusion in PubMed and all major indexing services

- Maximum visibility for your research

Submit your manuscript at www.biomedcentral.com/submit
Biomed Central 